\title{
Faculty Evaluations Provide Solutions to Online Teaching of Evidenced-Based Practice
}

\author{
Clarissa Silva ${ }^{1, *}$ \\ ${ }^{1} 582$ Oilfield Dr, Horizon City, Texas 79928, USA \\ *Corresponding author: 582 Oilfield Dr, Horizon City, Texas 79928, USA. Tel: \\ 1-210-332-3045. E-mail: pearl101524@gmail.com
}

Received: April 3, 2020 Accepted: May 18, 2020 Published: June 25, 2020

doi:10.5296/ije.v12i2.17303 URL: https://doi.org/10.5296/ije.v12i2.17303

\begin{abstract}
Background: The purpose of this report is to provide solutions to improving online course teaching for the challenging topic of Evidenced-Based Practice.

Evidence-based practice courses five weeks in length with assignments that would enlist the creativity of the student if allowed to conduct a clinical project.

Methods: The student was given a choice on a hypothetical patient and clinical topic to base their research on for the course. Virtual meetings and video recordings were used to conduct the course.

Results: An improvement from a 3.1 to a 3.8 on course evaluations and 3.9 on faculty evaluations by students which gave a conformation that the student obtained knowledge from this course online environment.

Conclusion: An understanding of the learner needs is incredibly important and an emphasis on audiovisual format which enhances knowledge acquisition of complex course content. As instructors, innovative thinking, and application of course content delivery is needed for today's student.
\end{abstract}

Keywords: evidenced-based practice, video, faculty evaluations, online course teaching, virtual meetings 


\section{Introduction}

Online learning is a challenge for undergraduate nursing students and faculty. As instructors, we teach what is expected and important in supporting our area of practice. Teaching evidence-based practice (EBP) has been challenging in an online format. An overview of how the previous course had been taught was conducted to plan the future content for teaching EBP online. The syllabus, assignments, and approved book for the course were assessed. A sense of redundancy in the approach to the entire course was noted where the first and second courses solely centered on the Patient Population, Intervention, Comparison, Outcome, and Time (PICOT) question (Polit \& Beck, 2018). While there is an appreciation that a good clinical question was necessary, EBP required more strategies to the delivery of course content so that students could appreciate the concepts. The course materials and resources provided by the publisher were researched and it was determined these courses were canned. Since the nursing program offered a master's level research course for EBP, the need for congruency in the undergraduate experience became necessary. The purpose of this report is to provide solutions to improving online course teaching for the challenging topic of EBP to undergraduate nursing students.

\section{Background}

Knowledge of EBP is essential to the safety and quality of care patients receive by nurses and healthcare providers. The competency of knowledge, attitudes, and behavior are important concepts the undergraduate nursing student must be able to utilize in learning EBP. Different learning approaches are needed for undergraduate nursing students to learn EBP (Oh \& Yang, 2019).

The understanding of the EBP concepts can be challenging for undergraduate nursing students to comprehend. Strategies for teaching EBP can make the difference in the transfer of knowledge from instructor to student. Teaching online can be a challenge in terms of the length of the course, size of the class, type of learning management system, and technology resources available for use to the instructor. Reliable textbooks containing understandable information for the undergraduate nursing student can make the difference between a content and disengaged student. Knowledge of technological systems is a sound approach to providing a successful experience for the educator and the student. The student experience of EBP course must be engaging and interesting to retain involvement. A willingness to explain content to various levels of learner is crucial to a good experience (Silva, 2020).

Considering undergraduate nursing EBP courses were offered in a five-week online format, the information in the book was compared to the publisher materials to establish a link in what nursing students were required to purchase. An analysis of the course catalog was conducted by comparing the course syllabi and mapping the course objectives to the student learning outcomes of the nursing program (Silva, 2020).

Strategies to enhance student engagement in the course were enlisted as well as technological support for those learners who needed extra support to comprehend the EBP information. 
There is limited information available and theoretical structure to determine the design of curricula in teaching EBP (Ramis, et. al., 2019).

\section{Review of the Literature}

In establishing a basis for using technology to improve the EBP course content, a review of the literature was conducted. Current research on improving online course instruction for EBP was examined. Data bases searched included ERIC, CINAHL, PubMed.gov, EBSCO host, and Academic Search to support this report with the latest available evidence on this topic.

Horvath, et al. (2019) posit the need for student orientation to the online course learning management system as well as any technical support resources that will be utilized by the student. Students who were organized, resourceful, and computer literate were more successful in the online course environment. Knowledge of the technology used in the online course was critical to success. The study sample size was limited and recommended further study.

Wandler and Imbriale (2017) recommended the use self-regulation by students for success in online courses with the incorporation of short- \& long-term goals. Videos of instructors were endorsed as a method of emphasizing written content. Instructors wanted the student to view videos and answer pre and post questionnaires to ensure the student viewed the video. Self-study logs were part of the study for reflection and goal attainment.

Accommodating the learner style of today's student includes adjusting in the pedagogical approach of online learners. Earle \& Myrick (2009) suggest the use of WebQuests which encourage using the internet for utilization of obtained information. The learner uses the information found to problem solve, analyze, synthesize, and evaluate. WebQuests promote reformation of traditional pedagogy through creating opportunities for the student to become innovators and creative thinkers. This study found an approach to keeping up with the millennial learner and assists this learner in assessment and evaluation of scholarly information discovered online.

Long et al. (2016) propose that practicing nurses lack the confidence to conduct research coursework. Many students are challenged in their ability to appraise and know when online health literature is trustworthy. Through the application of technology, EBP challenges are being addressed. A new tool serves as an access to evidence-based information via a cell phone, tablet or computer known as "EBR" (p. 60). This tool provides the ability of the student to search for clinical problems and provides supporting evidence. The EBR tool is a supplement to researching and not intended as a replacement for formal instruction or course textbook. The study proved useful for undergraduate students who were enrolled in EBP.

The mode of delivery has an impact of how nursing students learn evidence-base practice research and translate knowledge capacity. The study discusses the re-development of the course which focused on student satisfaction as changes were made to the delivery of the 
evidenced-base practice course content for undergraduate nurses. The students were studied over a year in a mixed-methods approach with improvements to student satisfaction with the implementation of experiential learning methods (Hickman, et al., 2014).

Sin \& Bliquez (2017) expressed that teaching EBP to undergraduate nursing students is a challenge. It is the teaching strategy that makes the difference. Strategies included the introduction of a good clinical question and its development. Formulating a problem statement and learning the art of selecting appropriate evidence in databases was offered in the course. Appraisal of the evidence and application were the suggested topics. Student presentation of papers to colleagues and award recognition were conducted which was a favorable experience for students. Creativity in course development and dissemination provide a gratifying augmentation to the experience and comprehension of EBP.

Cardoso, et al. (2019) conducted an intervention for teaching EBP to nursing students in the fourth semester and explored how students felt about the intervention. EBP was offered over 17 weeks with face to face and small group meetings. There were practical and mentoring strategies incorporated into the course. Students were content with the intervention but requested more mentorship.

Regarding student attitudes in learning nursing research in an online forum, Ramsay, et al. (2020) conducted a survey study to examine the thoughts of nursing students who take this course as an undergraduate nursing requirement. Nursing students expressed the value of education of research and understood the relevance to practice. Nursing students also appreciated the understanding of research terminology. While students went through the motion of completing the coursework for EBP research course, their attitudes were not positive in their interests in research and there was a disinterest in conducting research in future practice. Students consider the information of EBP difficult. Overall attitudes regarding research are hard to change and faculty should consider ever changing approaches to the development of EBP course content.

A unique approach to teaching online EBP to large groups of students includes the use of debates. This EBP course was designed to teach 200 students or more with all content presented at the beginning of the semester and leaving the latter part of the semester to conduct debates online. Students were given the case study and expected to research the topic and later present their findings and problem-solving solutions to the instructor in a continuous online debate. Large student groups of eight or more were divided with instructions on delegation of duties for the final project. This approach enabled the instructor to oversee the progress students were making and time to address any writing or adherence to scholarly work. The students used teamwork strategies and ownership for completing the assignment (Boyd, et al., 2015).

Strategies to teach EBP according to Ramis, et al. (2019) include the use of a combination of approaches. The information was obtained by researching systematic reviews. The information found embraced the use of journal clubs, small group discussions, and case study scenarios (p. 2). The study did not identify specific theories that support all aspects of teaching and student learning of EBP. However, Bandura's theory of Social Learning 
displayed significance in supporting the self-efficacy of the learner, since EBP requires that the learner have the intellectual aptitude to retain the competencies learned (Ramis, et al., 2019). Further study was recommended.

Teaching methods inclusive of a blended approach to teaching EBP embraced the use of lectures, team-based learning, computer-based learning, problem-based learning, group activity including student presentations (Oh \& Yang, 2019, p. 46). The participants included teaching EBP to nursing and medical students. The non-randomized study was conducted over a four-month period. All approaches were presented to the participants followed by pre and post questionnaires. The results showed blended strategies are needed to teach EBP to undergraduate nursing students. The approach of strictly using a didactic approach does not have a significant impact to teaching EBP to medical students (Oh \& Yang, 2019).

\section{Methods}

After completion of the preliminary analysis of the EBP courses, the course assignments were rewritten to be congruent with the assigned book readings. Assignments were chosen that would enlist the creativity of the student if they could conduct a true study on a clinical project. The student was given a choice on a hypothetical patient and hypothetical clinical topics to base their research on for the course.

Assignments for the first course were inclusive of discussion boards, selection of a hypothetical clinical topic, writing a PICOT question, conducting a relevant evidence search to answer a hypothetical clinical question, and writing a critique on a quantitative and qualitative articles (Polit \& Beck, 2018; Melnyk \& Fineout-Overholt, 2015).

In the second course, the student was expected write a discussion board about patient preferences and values, clinical practice guidelines and implementation of models of EBP. Students were required to create a recorded clinical environment poster presentation on a hypothetical clinical topic and create a dashboard display of the results on a hypothetical clinical topic (Melnyk \& Fineout-Overholt, 2015).

In reflection, the design of the first EBP course, the course was simple, and the students were expected to do well. However, after the first week students felt challenged and did not understand the instructions of the assignments.

After deliberating the possible approaches to this dilemma, considerations of how people learn became a factor. Since this was an online class, the enlistment of theory was used to solve this problem.

\section{Theoretical Framework}

Kolb (1984) theorized four learning styles affected by the social environment, educational experience, and cognitive structure of the person. The person learning travels through four stages to achieve learning inclusive of the concrete, reflective observation, abstract 
conceptualization, and active experimentation. Considering that learning takes place on a process continuum, the learner needed to be able to approach the task and then experience the emotional task of thinking and feeling about the task (Kolb, 1984). Assignments would need to provide experiences in the course that allowed for the student's experience, reflection, conceptualization, and testing to determine if effective learning were taking place.

\section{Interventions}

The interventions chosen were the incorporation of research terminology quizzes to assist in the understanding the words the student would see in the assignments and to support the reading/writing learner. A second intervention included the development and use of Kaltura video (2020) which were incorporated to enlist a visual example of the assignment, thus assisting the visual learner. A third intervention was the introduction of Cisco WebEx virtual Meetings (2020) which were used to invite those students with auditory and tactile learning needs. Emailing and texting were used to enhance communication among individual students who experienced extra clarification needs. The final intervention included a change to the EBP undergraduate book so that the same authors used in the undergraduate course was also utilized for the master's program for EBP. The book and assignments were changed to create a continuum, familiarity, and consistency with the authors from one undergraduate academic level of EBP to the graduate level of EBP.

The measures used for determining the validity and reliability of the changes made to the EBP courses was the use of faculty and course evaluations provided by Qualtrics (2020). The program uses both quantitative and qualitative methods to draw inferences from the student. Data was drawn from personal evaluation results over the period of three semesters.

\section{Results}

Students appreciated the Kaltura video (2020) and Cisco WebEx Meetings (2020) that ensured they were on the correct path to producing a good product and grade outcome. Students encouraged the retention of these approaches since communication within online courses can be challenging. Students used the qualitative opportunity to express a sense of supervision they felt was needed to guide their online learning experience as they could see the instructor on the Kaltura video (2020) or Cisco WebEx Meetings (2020), even though distance was an issue.

Qualtrics (2020) uses a 5-point Likert scale from strongly disagree to strongly agree for the data set and contains a qualitative section for students to express their feedback for improvement, strengths, and improvement for teaching. The Qualtrics course evaluations of how the students learned EBP and understand instructions began to improve. An improvement on the Qualtrics course evaluations went from a 3.1 in 2018 to a 3.8 and 3.9 on personal evaluations in 2019 by students which gave a sense of pride and relief that learning was required in this online environment. The program includes the results from one year to 
the next per semester.

\section{Discussion}

The key findings included student engagement when Kaltura video (2020) or Cisco WebEx Meetings (2020) were utilized in the EBP courses. Changing the book made it easier to understand EBP which was observed among positive qualitative comments of student evaluations. The association between the intervention and the outcomes are correlated in that more students were provided assignments in the EBP course. The impact of teaching in this approach to other nursing courses is that students are prepared to use EBP. While the context of future courses that students participate in may change, the EBP component remains consistent throughout the program. Students can implement EBP knowledge learned in completing future assignments in nursing program. The costs to implementing these changes in teaching EBP were negligible. The changes to the EBP course were merely an addition to the EBP courses from already approved electronic programs used within the nursing program.

It was difficult to find comparison studies utilizing the same approach to this report. The results of this report were marginally comparable to studies conducted by Wandler and Imbriale (2017) and Hickman, et al. (2014) although not in their entirety as this study used self-regulation as a major intervention. Sin \& Bliquez (2017) describe the current course approach to the presentation of EBP. The difference between the current report was the awards ceremony which were insightful. Ramsay, et al. (2020) survey study on nursing student attitudes toward nursing research showed some comparison to the current report on strategies to improving the online forum, however this study differed in inquiring about student attitudes of the study of research. Oh \& Yang (2019) recommend a blended approach to teaching EBP to undergraduate nursing and medical students.

Studies in the literature review were different as opposed to this report which discussed orientations, WebQuests, EBR's, mentorships, and debates as approaches to learning and application of EBP (Horvath, et al., 2019; Earle \& Myrick, 2009; Long et al.,2016; Cardoso, et al. 2019; Boyd, et al., 2015). The study by Cardoso, et al. (2019) was a face to face course and not an online format. Ramis, et al. (2019) was a systematic review of various suggestions drawn from the literature of which did not indicate an online approach to teaching EBP.

Many of the studies in the literature review were addressing the instruction of EBP and introducing innovative approaches for learners in the online forum. However, some studies provided the use of didactic experience with mentorships (Cardoso, et al.,2019). A blended approach to teaching EBP to undergraduate nursing students seems the best approach to maintain nursing student attention as it promotes more creativity to the introduction of EBP concepts (Oh \& Yang, 2019). The use of technology in an online forum compliments the approach to teaching EBP to undergraduate nursing students and creates a blended approach within online instruction. 


\subsection{Limitations}

The limitations in this report included the Qualtrics course evaluations. These faculty evaluations contain minimal student participation in evaluation of the course or instruction methods. Efforts to minimize and adjust for limitations include reinforcing the importance of the student feedback through the Qualtrics program.

\section{Conclusion}

In higher education, a canned course approach to teaching EBP could meet the basic learning needs of the undergraduate nursing student. However, due to the complexity of the EBP topic, an understanding of learner needs is incredibly important. Placing the expectations of the course in an audiovisual format enhances the understanding of complex course content. To sustain online nursing courses, a technical approach to student needs must be considered and utilized. Instructors need to be innovative in their approach to promote thinking and stay in alliance with the expectations of today's nursing student. Online education is challenging because the face to face component is absent. Communication must be technically emphasized. The use of technical programs is recommended as they can enhance the experience of the student and keep them engaged and provide a successful learning outcome. There is a need for further study and innovation in this field of online teaching, specifically if the EBP courses are going to be offered in an online format to undergraduate nursing students.

\section{References}

Boyd, M. R., Baliko, B., \& Polyakova-Norwood, V. (2015). Using debates to teach evidence-based practice to large online courses. Journal of Nursing Education, 54(10). 578-582.https://doi-org.libraryaccess.elpaso.ttuhsc.edu/10.3928/01484834-20150916-06

Cardoso, D., Rodrigues, M. A., \& Apostolo, J. (2019) Evidence-based practice educational program: A Portuguese experience with undergraduate nursing students. International Journal of Evidence-Based Healthcare, 17, S72-S74. https://doi.org/10.1097/XEB.0000000000000193

$\begin{array}{llll}\text { Cisco } \quad \text { Webex } & \text { (2020). } & \text { Retings. } & \text { Retrieved }\end{array}$ https://www.cisco.com/c/en/us/solutions/collaboration/compete/choose-cisco.html

Earle, V., \& Myrick, F. (2009). Nursing pedagogy and the intergenerational discourse. Journal of Nursing Education, 48(11), 624-630. https://doi.org/10.3928/01484834-20090716-08

Hickman, L.D., Kelly, H., \& Phillips, J. L. (2014). EVITEACH: A study exploring ways to Optimize the uptake of evidence-based practice to undergraduate nurses. Nursing Education in Practice, 14(6), 598-604. https://doi.org/10.1016/j.nepr.2014.05.013 
Horvath, D., Stirling, E., Bevacqua, J. Coldrey, M., \& Buultjens, P. (2019). Plan, prepare and Connect: How investing in understanding and tracking the evolving needs of online Students informs the development of target programs for transitions and success. Journal of University Teaching \& Learning Practice, 16(1), 1-16. https://ro.uow.edu.au/jutlp/vol16/iss1/4/

Kaltura (2020). Kaltura Personal Video Capture. Retrieved from https://corp.kaltura.com/products/video-for-business/personal-video-capture/

Kolb, D. (1984). Experiential Learning. Experience as the source of learning and development. Prentice Hall, Inc. Retrieved from https://www.researchgate.net/publication/235701029_Experiential_Learning_Experienc e_As_The_Source_Of_Learning_And_Development

Long, J. D., Gannaway, P., Ford, C., Doumit, R., Zeeni, N., Sukkarieh-Haraty, O., ... Song, H. (2016). Effectiveness of a technology-based intervention to teach evidence-based practice: The EBR tool. Worldviews on Evidence-Based Nursing, 13(1), 59-65. https://doi.org/10.1111/wvn.12132

Melnyk, B. M., \& Fineout-Overholt (2015). Evidence-Based Practice in Nursing Healthcare.Guide to best practice (3rd ed.). Wolters Kluwer. Retrieved from https://www.barnesandnoble.com/w/evidence-based-practice-in-nursing-healthcare-bern adette-melnk1119704177;jsessionid=6394D9127E7A32CC8EEC69B180595B5B.prodn y_store01-atgap14?ean=9781451190946

Oh, E. G., \& Yang, Y. L. (2019). Evidence-based nursing education for undergraduate students: A preliminary experimental study. Nursing Education in Practice, 38, 45-51. https://doi.org/10.1016/j.nepr.2019.05.010

Polit, D. F. \& Beck, C. T. (2018). Essentials of nursing research. Appraising evidence for nursing practice $\left(9^{\text {th }}\right.$ ed.). Wolters Kluwer. Retrieved from https://www.barnesandnoble.com/w/essentials-of-nursing-research-denise-f-polit-phd-fa an/1129424013? ean=9781496351296

Qualtrics. $^{\mathrm{XM}}$ (2020). The Leading Experience Management Software. Retrieved from https://www.qualtrics.com/

Ramis, M. A., Chang, A., Conway, A., Lim, D., Munday, J., \& Nissen, L. (2019). Theory-base strategies for teaching evidenced-based practice to undergraduate health students: a systematic review. BMC Medical Education, 19(267), 1-13. https://doi.org/10.1186/s12909-019-1698-4

Ramsay, A., Wicking, K., \& Yates, K. (2020). In what ways does online teaching create a positive attitude towards research in nursing students studying a first year evidenced-based practice undergraduate subject online? Nurse Education in practice, 44, 1-7. https://doi.org/10.1016/j.nepr.2020.102744

Sin, M. K., \& Bliquez, R. (2017). Teaching evidence based practice to undergraduate nursing 
Students. Journal of Professional Nursing, 33(6), 447-451. https://doi.org/10.1016/j.profnurs.2017.06.003

Wandler, J., \& Imbriale, W. (2017). Promoting undergraduate student self-regulation in online learning environments. Online Learning, 21(2), 1-16. https://doi.org:10.24059/olj.v21i2.881

\section{Copyright Disclaimer}

Copyright for this article is retained by the author(s), with first publication rights granted to the journal.

This is an open-access article distributed under the terms and conditions of the Creative Commons Attribution license (http://creativecommons.org/licenses/by/3.0/). 